\title{
ANALISIS KEKUATAN M. QUADRISEP FEMORIS TERHADAP RESIKO GANGGUAN KESEIMBANGAN POSTURAL
}

\author{
Aan Dwi Prasetio', Thontowi Djauhari' ${ }^{2}$ Rahayu ${ }^{3}$ \\ Fakultas Kedokteran Universitas Muhammadiyah Malang, Sawojajar 2, Kota Malang, 65154, Indonesia, \\ 087859899093 /aan.prasetio92@gmail.com;
}

\begin{abstract}
ABSTRAK
Analisis Kekuatan M. Quadrisep femoris Terhadap Resiko Gangguan Keseimbangan Postural. Latar Belakang : Kekuatan otot M. Quadrisep femoris dapat mempengaruhi kontrol tubuh saat berjalan. Kelelahan pada M. Quadrisep femoris dapat mempengaruhi gangguan keseimbangan postural. Tujuan : Mengetahui efek kekuatan M. Quadrisep femoris terhadap resiko gangguan keseimbangan postural. Metode Penelitian : Jenis observasional analitik cross sectional. Populasinya semua mahasiswa fakultas kedokteran Universitas Muhammadiyah Malang. sampel adalah mahasiswa laki-laki yang aktif berolahraga usia 18-24 tahun yang memenuhi kriteria inklusi. Analisis statistik dengan uji korelasi Spearman. Hasil Penelitian dan diskusi : dari 30 sampel, 22 orang memiliki fatigue index $>50 \%$ yang diukur dengan WCT, 5 orang (17\%) mengalami gangguan keseimbangan ditandai perubahan lama berdiri $>3$ detik pada One legged stance test, sedangkan 17 orang lainnya (57\%) mengalami sedikit perubahan keseimbangan dengan perubahan lama berdiri ? 3 detik pada One legged stance test. Hanya 8 orang dari total sampel $(27 \%$ ) yang memiliki fatigue index $<50 \%$, perubahan keseimbangan dengan perubahan lama berdiri $<3$ detik pada One legged stance test. Dari analisis korelasi spearman menunjukkan ada hubungan yang signifikan antara WCT dengan One legged stance test $(\mathrm{p}<0,05)$. Kesimpulan : Penurunan kekuatan M. Quadrisep femoris akan meningkatkan resiko gangguan keseimbangan postural.
\end{abstract}

\section{ABSTRACT}

Strength Analysis of M. Quadrisep femoris Against Risk Postural Balance Disorders. Background: The strength of M. Quadrisep femoris can influence postural control when walk. Fatigue of M. Quadrisep femoris can influence on the risk of postural balance disorders. Objective: Determine the effect of strength of $\mathrm{M}$ Quadrisep femoris on the risk of postural balance disorders. Method: cross sectional analytic observational. The population is all students in faculty of medicine University of Muhammadiyah Malang. Sampel is students who actively exercise aged 18-24 years and met the others of inclution criteria. Statistical analysis used by Spearman correlation test. Result and discussion: From 30 sampel in this research, 22 peoples had fatigue index $>50 \%$ that measured by WCT, there are 5 people $(17 \%)$ had postural balance disorders that have change of long stand $>3$ second in One legged stance test, meanwhile 17 people (57\%) experienced a slight change in the balance because had change of long stand (duration) $<3$ second in One legged stance test. Only 8 peoples from all sampel (27\%) who had a fatigue index $<50 \%$ and a slight change in the balance with change of long stand (of duration) $<3$ second in One legged stance test. from analysis Spearman correlation test indicate there is significan relationship between WCT and One legged stance test $(p<0,05)$. Conclusion: Discharged of muscle strength can increasing on the risk of postural balance disorders.

Key words: the strength of M. Quadrisep femoris, postural balance disorder

\section{PENDAHULUAN}

M. Quadrisep femoris tersusun dari empat musculus $M$. Rectus femoris, M. Vastus lateralis, $M$. Vastus medialis, $M$. Vastus intermedius. M. Rectus femoris adalah bagian dari $M$. Quadrisep femoris yang paling sering mengalami gangguan, karena $M$. Rectus femoris termasuk serabut otot putih tipe 2 yang dapat menghasilkan energi secara cepat untuk aktivitas berat. $M$. Rectus femoris bagian yang paling mudah mengalami cedera saat melakukan gerakan cepat seperti lompat tinggi, menendang bola, atau ketika adanya hambatan saat kontraksi, misal ketika dua pemain bola sama-sama menendang bola dalam waktu bersamaan. Studi kasus di Inggris di tahun 2010, seorang laki- laki 17 tahun mengalami cedera pada $M$. Quadrisep femoris saat bermain bola, setelah mendapat terapi dari fisioterapis dan mendapat manajemen non operatif selama 15 hari tetap tidak dapat memulihkan fungsinya seperti semula (Taylor, 2012).

Penelitian pada subyek dewasa muda yang dilakukan oleh Davidson BS, et al pada tahun 2009 di departemen neurosciense NTNU Norwegia, menunjukkan kelelahan pada otot tungkai bawah (extremitas inferior) dapat merubah posisi dan gaya berjalan. Kelelahan pada M. Quadrisep femoris dapat mengubah gaya berjalan yang cenderung mudah tergelincir (Helbostard, 2010). Para peneliti di University of Connecticut dan Indiana University melaporkan penurunan keseimbangan pada satu kaki memprediksi risiko cedera pada usia muda. Risiko keseleo pergelangan kaki menjadi lebih dari dua kali lipat antara siswa SMA dan atlet perguruan 
tinggi yang tidak bisa menjaga keseimbangan pada satu kaki saat mata tertutup (Burke, 2011).

\section{BAHAN DAN METODE}

Alat-alat yang digunakan yaitu formulir isian dan alat tulis untuk mencatat data, Spygnomanometer air raksa, Stetoskop, Timbangan, Meteran, Jam tangan, Ergocycle, Kartu snellen dan pin hole.

Pemeriksaan Wingate Cycle Test (WCT) dengan cara beban ergocycle ditentukan dengan mengalikan BB (kg) dengan 0.075, Ketinggian tempat duduk sepeda (sadel) diatur sehingga pada saat pedal dibawah tungkai dalam posisi sedikit fleksi. Ketinggian sadel dicatat. Subjek diminta untuk mengayuh sepeda selama 3 menit sebagai pemanasan dengan intensitas yang cukup untuk menaikkan denyut jantung 150-170 kali/ menit. Setelah pemanasan istirahat selama 3 menit. Subjek diminta mengayuh secepat mungkin setelah aba-aba "mulai". Beban sepeda ditingkatkan secara cepat dalam waktu 2-5 detik sampai mencapai beban yang sesuai dengan perhitungan beban. Saat kecepatan maksimal, pada monitor tercatat jumlah putaran (rotasi) pedal sepeda tiap 5 detik. Subjek diminta mengayuh selama 30 detik. Bila sebelum 30 detik subyek kelelahan maka jumlah putaran rotasi pedal akan tetap diukur 5 detik sebelum subyek berhenti. Setelah 30 detik subjek diminta menghentikan WCT. Beban dikembalikan ke 0. Subjek melanjutkan One Legged (Single Limb) Stance Test. Jeda antara penghentian WCT dengan One Legged (Single Limb) Stance Test tidak boleh lebih dari 3 menit.

One Legged (Single Limb) Stance Test, berfungsi menilai keseimbangan statik pada subjek. Dengan cara; Subjek diminta berdiri dengan kedua kakinya berdekatan satu dengan yang lain. Lalu subjek diminta menutup matanya, sambil mengangkat satu kaki yang tidak menjadi tumpuan dan difleksikan sekitar 45 derajat, kemudian waktu dicatat sampai subyek hilang keseimbangan. Tes diulangi sebanyak tiga kali untuk mengambil rata-rata waktunya. Analisis disesuaikan dengan indikator pemeriksaan One Legged (Single Limb) Stance Tes.Rata-rata waktu normal dengan menutup mata:

$$
\begin{aligned}
& \text { usia 18-39 }=9 \text { detik } \\
& \text { usia 40-49 }=7 \text { detik } \\
& \text { usia 50-59 }=5 \text { detik } \\
& \text { usia }>60=3 \text { detik }
\end{aligned}
$$

\section{HASIL DAN PEMBAHASAN}

Dari hasil pengukuran TB didapatkan TB tertinggi adalah $175 \mathrm{~cm}$ dan TB terendah adalah $156 \mathrm{~cm}$. jumlah TB terbanyak adalah $166 \mathrm{~cm}$ atau 23,33\% dari total sampel. Pada grafik, penurunan keseimbangan banyak terjadi pada subyek yang memiliki TB $166 \mathrm{~cm}$ yaitu sebanyak 6 orang dan memiliki fatigue index $>50 \%$ pada 5 orang. Sedangkan jumlah sampel terbanyak kedua yang mengalami penurunan keseimbangan tubuh pada subyek yang memiliki TB 164 $\mathrm{cm}$ dan $165 \mathrm{~cm}$ masing-masing berjumlah 4 orang. Pada sampel yang memiliki TB $159 \mathrm{~cm}, 168 \mathrm{~cm}$ dan $173 \mathrm{~cm}$ tidak terjadi penurunan keseimbangan tubuh walaupun terdapat sampel yang memiliki fatigue index $<50 \%$.
Tabel 1. Data Tinggi Badan Sampel Terhadap Perubahan Keseimbangan.

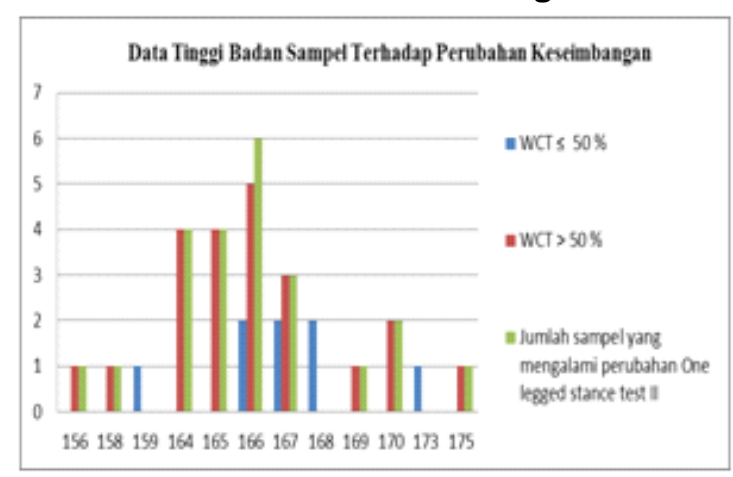

Pada hasil pengukuran BB dari 30 sampel, BB terrendah adalah $52 \mathrm{~kg}(3,33 \%)$ dan BB tertinggi adalah $70 \mathrm{~kg}(3,33$ $\%$ ). Sebaran jumlah subyek pada tiap-tiap kelompok BB pada tabel 5.3 menunjukkan hampir merata. Jumlah sampel terbanyak dengan BB $58 \mathrm{~kg}$ sekitar $20 \%$ dari total sampel. Pada grafik terlihat jumlah sampel yang memiliki fatigue index $>50 \%$ dari hasil pemeriksaan WCT, terbanyak pada sampel yang mempunyai BB $57 \mathrm{~kg}$ dan $58 \mathrm{~kg}$, dimana kedua kelompok BB ini juga memiliki perubahan keseimbangan yang paling banyak dari total sampel yang ada. Pada sampel yang memiliki BB $64 \mathrm{~kg}$ tidak mengalami perubahan keseimbangan saat melakukan One legged stance test II walapun memiliki fatigue index $<50 \%$.

\section{Tabel 2. Data Berat Badan Sampel Terhadap} Perubahan Keseimbangan.

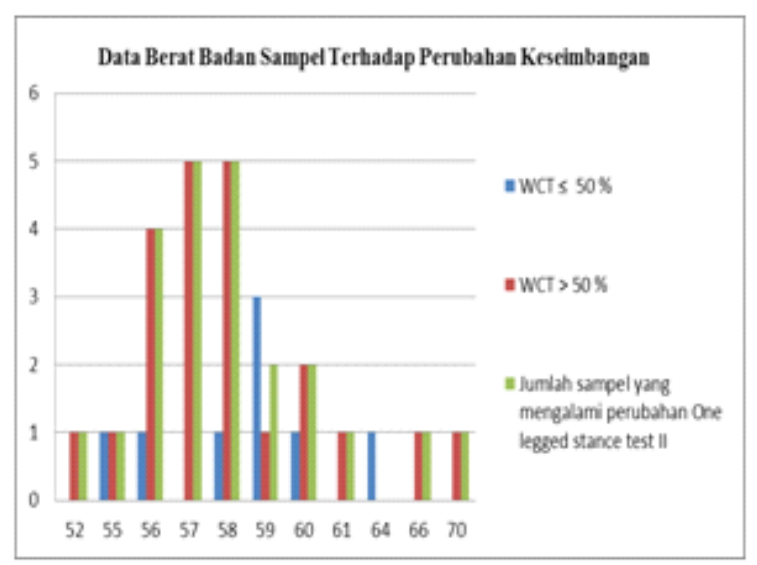

Pada tabel 3. indek massa tubuh terbanyak pada sampel adalah $20-21 \mathrm{~kg} / \mathrm{m} 2$ (73.33\%). Dari total 22 sampel yang mengalami perubahan keseimbangan, jumlah sampel yang mengalami penurunan keseimbangan pada kelompok IMT $20-21 \mathrm{~kg} / \mathrm{m} 2$ dan kelompok IMT 21,01-24 kg/m2 sama, yakni ada 11 orang. Namun jumlah sampel yang memiliki fatigue index $>50 \%$ terbanyak pada IMT 20-21 $\mathrm{kg} / \mathrm{m} 2$ yaitu sebanyak 13 orang dan jumlah sampel yang memiliki fatigue index $<50 \%$ terbanyak juga ada pada kelompok sampel yang memiliki IMT 20-21 kg/m2 berjumlah 5 orang. 
Tabel 3. Data IMT (Index Massa Tubuh) Sampel Terhadap Perubahan Keseimbangan

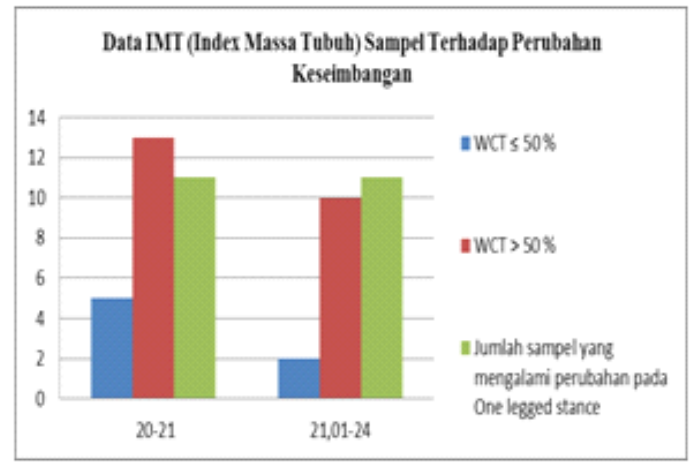

Pada saat dilakukan pemeriksaan provokasi WCT berat beban ergocycle yang digunakan disesuaikan dengan 7,5\% dari berat badannya. Peneliti memakai standar beban luar negeri yaitu 7,5\% dari berat badan subyek penelitian, Sehingga didapatkan rata-rata berat ergocycle adalah 4,36 kp, dengan beban tertinggi 4,95 dan beban terringan pada pemerikaan ini adalah 3,9. Pada putaran pedal 5 detik pertama rata-rata jumlah putaran pedal yaitu 17,37 rpm dengan nilai tertinggi $27 \mathrm{rpm}$ dan putaran paling pelan adalah 10 rpm sedangkan pada putaran pedal 5 detik terakhir rata-rata kecepatan menurun menjadi 7,03 dengan kecepatan tertinggi 16,57 rpm dan yang paling pelan 3,24 rpm. Pada perhitungan index kelelahan WCT, rata-rata subyek memiliki index kelelahan $58 \%$ SD 0,18. Index kelelahan tertinggi sebesar $85 \%$ dan index kelelahan terendah adalah $18,18 \%$. Semakin tinggi angka index kelelehan maka subyek tersebut semakin mudah lelah.

\section{Tabel 4. Hasil Pengukuran Keseimbangan One legged (single limb) test}

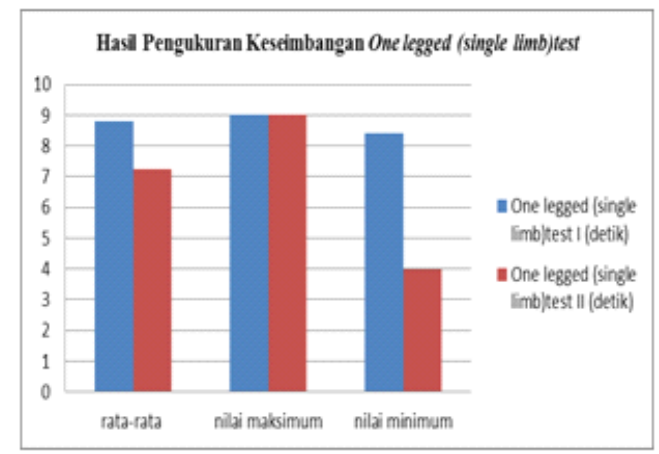

Pada saat dilakukan pemeriksaan One legged (single limb) I untuk memastikan tidak adanya gangguan keseimbangan pada subyek sebelumnya, didapatkan waktu tertinggi adalah 9 detik sedangkan waktu terendah adalah 8,6 detik. Rata-rata pada pemeriksaan One legged (single limb) I adalah 8,81 detik. Hasil dari pemeriksaan One legged (single limb) II didapatkan rata-rata waktu lama berdiri 7,23 detik, dengan waktu terlama berdiri 9 detik dan waktu tercepat 4 detik. Dari hasil ini terlihat perubahan keseimbangan yang cukup drastis bila dibandingkan dengan tes keseimbangan One legged (single limb) I. Hasil One legged (single limb) II dipengaruhi dari pemeriksaan WCT yang dilakukan sebelumnya.
Tabel 5. Prosentase Selisih One legged (single limb) Terhadap WCT

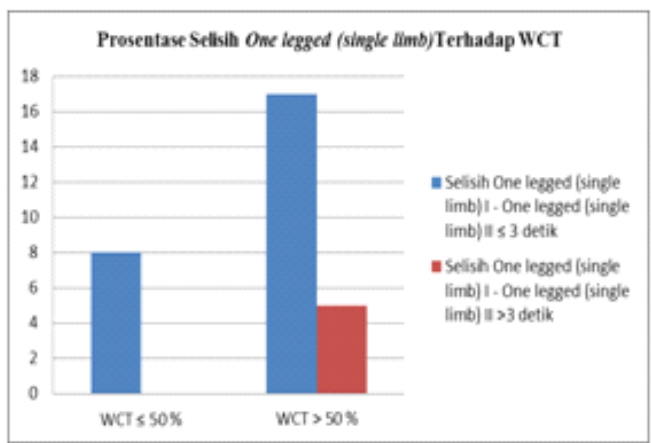

Hasil penelitian menunjukkan terdapat perubahan nilai One legged (single limb) akibat WCT. Perubahan hasil tes keseimbangan One legged (single limb) terbanyak pada 25 orang atau $83 \%$ yang memiliki fatigue index $>50 \% .17$ orang $(57 \%)$ diantaranya mengalami sedikit perubahan lamanya berdiri ? 3 detik pada One legged (single limb) stance test, sedangkan 5 orang sisanya mengalami perubahan lamanya berdiri $>3$ detik. Hanya ada 8 orang dari total sampel $(27 \%)$ yang memiliki fatigue index ? $50 \%$ disertai perubahan lamanya berdiri ? 3 detik pada One legged (single limb) stance test.

Berdasarkan hasil analisis korelasi Spearman pada tabel di atas, diketahui bahwa $r$ hitung $>r$ table $(0,596>0,362)$ atau nilai signifikansi $<$ taraf nyata $5 \%(0,001<0,05)$ maka dapat disimpulkan bahwa terdapat hubungan yang signifikan antara WCT dengan One legged. Koefisien korelasi yang terbentuk yaitu sebesar 0,596. Kategori korelasi ini berada pada kategori sedang antara 0,4 -0,599. Artinya, terdapat hubungan yang signifikan sebesar 59,6 \% antara kekuatan M. Quadrisep femoris dengan keseimbangan postural, dimana M. Quadrisep femoris mempengaruhi keseimbangan tubuh sebesar 59,6\% sedangkan 40,4\% sisanya dipengaruhi oleh variabel lain yang tidak diteliti. Karena koefisien korelasi negatif, berarti semakin tinggi fatigue index maka keseimbangan akan semakin menurun, demikian pula sebaliknya.

Berdasarkan analisis data didapatkan nilai korelasi 0,596 atau memiliki tingkat korelasi sebesar 59,6 \% termasuk kategori sedang, artinya M. Quadrisep femoris mempengaruhi keseimbangan postural sebesar 59,6\% dan 40,4\% sisanya dipengaruhi oleh variabel lain yang tidak diteliti. Pada pemeriksaaan One Legged (Single Limb) Stance Test dalam menilai keseimbangan postural banyak faktor yang mempengaruhi antara lain kondisi tubuh saat tes, kebiasaan olahraga dan intensitas latihan olahraga. Selain itu, keseimbangan postural juga disusun oleh banyak sistem seperti sistem somatosensoris, efektor dan otak. Kelelahan M. Quadrisep femoris dapat dipengaruhi oleh kelelahan otot-otot extremitas inferior lainnya. Hal ini didukung dari artikel penelitian Helbostard yang menunjukkan hanya ada satu penelitian investigasi dari Moore JB dalam bukunya Acute effect of a single bout of resistence exercise on postural control in elderly person,menjelaskan efek kelelahan pada Quadrisep femoris terhadap gangguan keseimbangan postural tidak bisa dipastikan oleh kelelahan M. Quadrisep femoris saja, namun kombinasi dari seluruh otot di extremitas inferior, persendian dan lutut (Helbostard, 2007). 
Hasil penelitian mengenai Fatigue index setelah melakukan One Legged (Single Limb) Stance Test II menunjukkan makin rendah fatigue index $(10 \%-50 \%)$, maka semakin lama subyek dapat berdiri pada One Legged (Single Limb) Stance Test. Sedangkan pada subyek yang memiliki fatigue index lebih besar (> 60\%) akan mengalami gangguan keseimbangan sehingga mudah jatuh. Hasil penelitian ini menunjukkan bahwa adanya hubungan yang bermakna antara kekuatan M. Quadrisep femoris dengan keseimbangan postural. Pada hasil penelitian didapatkan rata-rata fatigue index pada laki-laki adalah 58,00 \% dengan SD 0,18 fatigue index maksimal yaitu $85 \%$ dan minimum $18,18 \%$. Hal ini hampir sama dengan hasil penelitian Maud dan Schultz (1989) pada usia 18-20 tahun dengan protokol WCT menunjukkan fatigue index pada laki-laki adalah 70,6 \%. Penelitian Assmussen E (1999) pada usia 17-21 tahun dengan protokol WCT juga menunjukkan hasil yang mendekati yaitu 69,8\% pada laki-laki, tetapi mereka mengkaitkan fatigue index dengan kejadian osteoartritis (Assmussen E, 1999).

Hubungan yang bermakna antara fatigue index, skala kelelahan otot ekstrimitas bawah dengan lama subyek berdiri pada saat one legged stance test II $(p<0,05)$ dapat dideskripsikan makin tinggi angka fatigue index atau skala kelelahan ekstrimitas bawah, maka besar pula risiko kegagalan melakukan one legged stance test II / keseimbangannya akan terganggu, begitu pula sebaliknya. Hal ini sesuai dengan penelitian Phillip A Gribble dkk (2002) yang juga meneliti efek kelelahan otot ekstrimitas bawah terhadap kontrol postural pada mahasiswa usia 21-22 tahun dengan intervensi protocol Cybex yaitu membuat kelelahan otot lutut, angkel dan panggul secara isokinetik pada bidang sagital, lalu diukur kontrol postural secara statis dengan berdiri sebelah kaki dengan mata terbuka selama 30 detik. Hasil penelitian menunjukkan adanya kelemahan otot pada lutut dan panggul yang memiliki efek yang kurang baik terhadap kontrol postural. Disimpulkan bahwa kelelahan otot ekstrimitas bawah terutama pada regio femoris dapat menimbulkan kelemahan kontrol keseimbangan postural secara mendasar, yang diduga melalui mekanisme: melemahnya reseptor propioseptif dan kinestetik pada sendi dengan cara meningkatkan ambang batas rangsang muscle spindle (Gribble, 2004).

Dari hasil penelitian ini, peneliti dapat menunjukkan adanya kelemahan pada otot ekstrimitas inferior, terutama M. Quadrisep femoris dapat mengangu keseimbangan postural secara mendasar, yang diduga melalui mekanisme : melemahnya reseptor propioseptif dan kinestetik pada sendi dan meningkatkan ambang batas rangsang muscle spindle, mematahkan umpan balik afferent dan secara berurutan mengubah kesadaran posisi sendi. Dugaan ini perlu dipastikan dengan penelitian-penelitian lebih lanjut.

Dalam melakukan penelitian ini terdapat beberapa keterbatasan, antara lain, Terdapat faktor- faktor resiko lain yang tidak disertakan selama penelitian, misalnya kebiasaan sarapan, perbedaan frekuensi dan intensitas latihan / olahraga pada setiap subyek penelitian. Selain itu, terbatasnya referensi penelitian maupun artikel terbaru yang berkaitan langsung antara efek penurunan kekuatan otot Quadrisep femoris terhadap resiko gangguan keseimbangan postural. Dari hasil penelitian, gangguan keseimbangan postural tidak dapat dipastikan hanya karena penurunan kekuatan dari M. Quadrisep femoris saja, tapi bisa dipengaruhi oleh penurunan kekuatan otot pada bagian lain seperti pada regio cruris dan persendian pada lutut dan pergelangan kaki.

\section{SIMPULAN}

Ada hubungan yang signifikan antara kekuatan $\mathrm{M}$. Quadrisep femoris dengan resiko gangguan keseimbangan postural, dengan mengukur lamanya berdiri pada One legged stance test II didapatkan hasil sebesar 59,6\%. Semakin tinggi fatigue index yang diukur dengan WCT maka semakin rendah kemampuan untuk menjaga keseimbangan tubuh dan sebaliknya.

\section{DAFTAR PUSTAKA}

Alexander Nb, Taffet GE, Steven JE, Lee SC, Pearce KM, Snyder-Mackler L, Binder-Macleod SA. 2010. Bedsideto-Bench Conference:Research Agenda for Idiopaic fatigue and Aging. JAGS 2010,58:967-75

Asmussen, E. 1999. Muscle Fatigue. American Scientist

Battinelli, T. 2000. Physique, Fitness and Performance 1st Ed, USA. CRC Press

Burke, Rojas. 2011. Health Test: One-leg balance skill can warn of injury risk, Viewed oktober 2013, <http:// www.oregonlive.com/health/index.ssf/2011/01/ health_test_one-leg_balance_sk.html >

Bohanon, R.W. 1987. Gait Peformance of Hemiparetic Stroke Patients. Arch Phys Med Rehabil

Dahlan, M.S. 2009. Statistik Untuk Kedokteran dan Kesehatan, Salemba Medika Jakarta,

Davidson BS, Madigan ML, Nussbaum MA, Wojcik LA. 2009. Effects of localized muscle fatigue on recovery from a postural perturbation without stepping. Gait Posture 29:552-7

De Lateur BJ, 1996. Therapeutic exercise in Braddom RL: Physical medicine and rehabilitation 2nd ed. Philadelphia: WB Saunders, 480-519

Downey, J.A.1999. The Physiological Basis Of Rehabilitation Medicine 2nd ed. Boston. Butterworth Heinemann

Gribble, P.A, Hertel J. 2004. Effect of Lower Extremity Muscle Fatigue On Postural Control. Arch Phys Med Rehabil

Gunarto, S. 2005. Pengaruh Latihan Four Square Step Terhadap Keseimbangan Pada Lansia, FK UI, Jakarta.

Guyton, Arthur C. 2012. Buku Ajar Fisiologi Kedokteran. Jakarta. Penerbit EGC

Helbostard J1, Leirfall S, Moe-Nilssen. 2007. Physical fatigue affects gait characteristics in older persons. J Gerontol A boil Sci, 62:1010-5

Horton, M.G and Terry.Hall. 1989. Quadriceps femoris Muscle Angle: Normal Values and Relationships With Gender and Selected Skeletal Measures, viewed januari 2013, <http://ptjournal.apta.org/content/69/11/ 897>

Indriani. 1999. Pengaruh Latihan Braindt Daroff Pada Keseimbangan Postural Penderita Vertigo Posisi Paroksimal Jinak, FK UI, Jakarta 
Ismael, Sofyan. 1995. Dasar-Dasar Metodologi Penelitian Klinis, Binarupa Aksara, Jakarta

Jones, K and Barker.K. 1996. Human Movement Explained. Oxford. Butterworth Heinemann

Kirekendall, D.R, Gruber JJ, Johnson RE. 2002. Measurement and Evaluation for Physical Educator 2nd Ed Champaign: Human Kinetic, viewed februari 2013, <www.elsevier.com/locate/clinbiomech >

Konishi, Yu, Miyamoto N, Wahkahara T, kawakami Y. 2009. Possible Mechanism of Quadriceps femoris in Patients with Ruptured Anterior Cruciate Ligament. Tokyo. Department of Life Science, University of Tokyo

Kornetti DL, Shields RK. 2004. Rating Scale Analysis of The Berg balance Scale. Arch Phys Med Rehabil

Lanza, IR. Larsen, RG, Kent-Braun JA. 2007. Effect of old age on human skeletal muscle energetic during fatiguing contractions with and without blood flow. J physiol 2007, 583:1093-105

Latty, P. 2009. Factors That May Contribute to Difficulties in Walking or Maintaining Posture, and Falls in Elderly, viewed januari 2013, <www.Instruct1. cit.cornell.edu/courses/psych431/student98pwl2/ mobility.html >

Mademli, L. Arampatzis,A. 2008. Mechanical and morphological properties of the triceps surae muscle tendon unit in old and young adults and their interaction with a submaximal fatiguing contraction. J Electromyogr Kinesiol 2008, 18:89-98

Malawer, M and Sugarbaker, P. 2001. Quadriceps Muscle Group excision. Malawer Chapter 14

Moeloek, D. 1984. Dasar Fisiologi Kesegaran Jasmani dan Latihan Fisik, Balai Penerbit FK UI, Jakarta

Moore JB, Korff T. 2005. Acute effects of single bout of resistance exercise on postural control in elderly persons. Percept Mot Skill: 100:725-33

Ozturk, M, Ozer K, Gokce E. 1998. Evaluation of Blood Lactate in Young men after Wingate Anaerobic Power Test. Eastern Journal of Medicine 3

Pearson, B. 2009. Short vs Long Length of Rectus femoris During Eccentric Exercise in Relation to Muscle Damage in Healthy Males, viewed januari 2013, $<$ www.pearsoneducation.com>

Pollock, M.L, Wilmore JH. 2011. Exercise in health and Disease 2nd ed. Philadelphia. WB Saunders

Putra, B. 1996. Manfaat Latihan Metode Brandt Daroff Pada Penderita Benign Paroksimal Posisional Vertigo, FKUI, Jakarta

Rodriguez, I, Boulic R, Meziat D. 2010. A Joint-Level Model of Fatigue for The Postural Control of Virtual Humans, viewed januari 2013, <www.epfl.ch/publications/pdf>

Rohan. 2010. Fatigue in Skeletal Muscle, viewed januari 2013, <www.rohan.sdsu.edu/course/ens304/ public_html/section1/Fatigue.htm>

Rosenberger. 2010. Wingate Anaerobic Test Calcualtions, viewed januari 2013, <www.hup.sjsu.edu/faculty/ wingate.htm>

Rowland, T.H. 1996. Developmental Exercise Physiology Champaign : Human Kinetics, viewed februari 2013, $<$ www.elsevier.com>
Segal, Neil A. 2011. Obesity and Knee Osteoarthritis Are Not Associated with Impaired Quadrisep Specific Strength. NIH Public Access 3(4):314-323.

Serrao, F, Brubaker, M, Torner JC. 2007. Assesment of The Quadriseps femoris Muscle in Woman After Injury Induced By Maximal eccentric Isokinetic Exercise With Low Angular Speed. Sao Carlos. Department of Physical Therapy, Sao Paulo University

Sharkey, B.J. 2002. Physiology Of Fitness Champaign: Human Kinetic, viewed februari 2013 , $<$ www.elsevier.com>

Sidharta, P. 2005. Neurologi Klinis Dasar, Dian Rakyat, Jakarta

Snell, Richard. 2006. Anatomi Klinik untuk Mahasiswa Kedokteran, Penerbit EGC, Jakarta

Stavrianeas, S. 2003. Instruction for The Wingate Cycle Tes Exercise Physiology Laboratory. Willamette University Sugiyono. 2007. Statistika Untuk Penelitian. Bandung. Penerbit: CV. Alfabeta

Suleman, A. 2002. Exercise Phisiology, viewed januari 2013, $<$ www.emedicine.com>

Taylor, C. 2012. Repair of Rectus femoris Rupture with LARS Ligament. Plymounth. Trauma and Orhopedics Departement, Derriford Hospital

Vaughan, D.G, Asbury T, Riordan-Eva P. 1995. Oftalmologi Umum Edisi 14, Widya Medika, Jakarta 